\title{
Oil, water and health care - a difficult mix
}

$\mathrm{S}$ enior laundry man Stephen Prah is elated to fetch water from a tap, even though it's coming through leaking pipes.

It's a far cry from a scant 10 months ago, when the 43-year-old had to schlep water from a borehole about a kilometre away from the town of Dixcove's Nana Hima Dekyi Hospital, located in the Ahanta West district of the western region of Ghana. Although the area was once known primarily for its beaches and lagoons, crocodile ponds and plantations, it's now often afflicted by drought and lies in the heart of oilfields discovered in 2007. Dixcove has become an oil boomtown and the district now has a population of 131020 , an increase of about 35000 over a decade ago.

"This water has come as a big relief to us," says Prah, who has been washing hospital laundry for 22 years. "Since the construction of the hospital [in 1972], the galvanized copper pipes have not been replaced, so even the new tap water continually leaks badly."

Running water was made possible in 2010 when a rural water project created a local reservoir from which the hospital could tap water. Until then, it had to rely on rainwater collected onsite, or the water hauled from the distant borehole.

Water is among the many challenges that bedevils the only hospital in the Ahanta West district. It now must provide care for the massive influx of workers and investors in the booming oil industry, while handling the potential impacts that the boom may have on local residents, who for years quietly earned their livelihoods primarily from the sea.

Health hazards from environmental pollution are a concern, says Dr. Simon Osei Frimpong, the hospital's only physician and medical superintendent. "Communities in the Ahanta West district near the oil-drilling sites are likely to suffer from environmental pollution and its attendant disease - including those that affect the lungs - if adequate measures are not put in place."

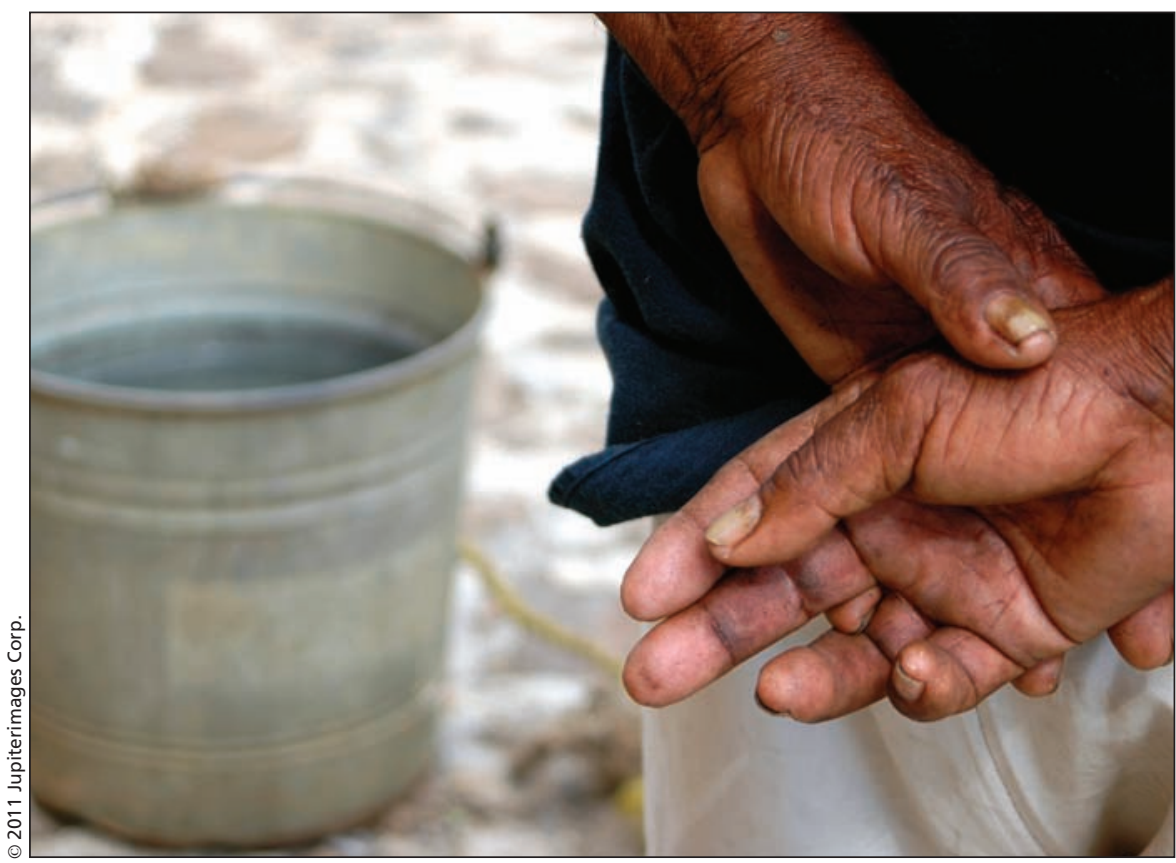

Running water was made possible at the Nana Hima Dekyi Hospital in Dixcove, Ghana in $\mathbf{2 0 1 0}$ when a rural water project created a local reservoir from which the hospital could tap water. Until then, it had to rely on rainwater collected onsite, or water hauled from a distant borehole.

Until now, Frimpong says skin diseases, including a neglected tropical disease called Buruli ulcer, and malaria have been the facility's primary challenge, and stock in trade.

"Most of the skin diseases may be traced to lack of running water or good hygiene in the communities," he adds. "Even hygiene in the hospital is questionable: When patients come to the hospital, their caregivers have to fetch water from a borehole about a kilometre from the hospital, and they often try to do everything with fewer buckets of water."

The region's endemic water problem motivated Canadian psychiatric nurse Michelle Labossiere Brandt to help establish a nonprofit organization - the Rhythm International Foundation, based in Edmonton, Alberta - with the goal of revitalizing the 52-bed hospital.

"I was in Busua beach [about 15minute drive from Dixcove] in 2009 when I contracted malaria and fever. I went to the hospital and realized they do not have even running water," says
Brandt, president of the foundation. "Incidentally, bathing in running water in the hotel where I stayed helped me recover, so I felt the need to help provide running water for patients and staff of the hospital."

Since its official registration in January 2010 , the foundation has raised $\$ 5000$ out of a targeted $\$ 25000$ and hopes to present a cheque to the hospital in July 2011.

Commercial oil production, which officially began Dec. 15, 2010, is only adding to the hospital's burdens, officials say.

"The oil find is attracting many visitors and workers to the district but we are not adequately resourced to cater for the health needs of the people," says Habib Ganiyu, the hospital's administrator. "We do not have a functioning kitchen, so patients bring their own food to the hospital. Our emergency department has only one ambulance, which is about 13 years old and is therefore very weak." 
Frimpong laments a lack of accommodation for hospital staff, which makes it difficult to recruit health care workers. "We have the least number of staff in the whole [Western] region. We don't have an anesthetist in this hospital yet we do surgeries here. I just pick some nurses and instruct them as to what to do while I do the surgeries."

Others are concerned about the impact the oilfields will have on local nutrition and food supplies, and ultimately, the health of fisherman and fishmongers. Residents of the area rely heavily on fish for their protein, so a shortage may lead to malnutrition.

"Some red lights have been used to signal areas in the sea where the fishermen should not catch fish, "says 67year-old Nana Kojo Krah, chief fisherman of Lower Dixcove. "Unfortunately, the red lights have attracted most fish there, thus reducing the yield of fishermen. If this trend continues, and we are not compensated by the government, we would stop fishing."
Fishmonger Mame Efua Mansa says that "now the fishermen don't get enough fish for us to buy and sell. So something has to be done about it otherwise we cannot live in this community."

The many problems have left local hospital staff appealing for international help. "If any individual or organization comes to our aid, we would be very happy and grateful," says Prah. Bernard Appiah, Accra, Ghana

CMAJ 2011. DOI:10.1503/cmaj.109-3794 